\title{
Study on key performance parameters of hydro-pneumatic tensioner for top tensioned riser
}

\author{
Baiquan Chen ${ }^{\mathrm{a}, \mathrm{b}}$, Jianxing $\mathrm{Yu}^{\mathrm{a}, \mathrm{b}}$, Yang $\mathrm{Yu}^{\mathrm{a}, \mathrm{b}, *}$, Lixin $\mathrm{Xu}^{\mathrm{a}, \mathrm{b}}$, Shuai $\mathrm{Hao}^{\mathrm{a}, \mathrm{b}}$, Chen $\mathrm{Wu}^{\mathrm{a}, \mathrm{b}}$, Han $\mathrm{Wu}^{\mathrm{c}}$ \\ ${ }^{a}$ State Key Laboratory of Hydraulic Engineering Simulation and Safety, Tianjin University, Tianjin 300350, China \\ ${ }^{\mathrm{b}}$ Collaborative Innovation Center for Advanced Ship and Deep-Sea Exploration, Shanghai Jiaotong University, Shanghai 200240, China \\ ${ }^{\mathrm{c}}$ Key Laboratory for Mechanics in Fluid Solid Coupling Systems, Institute of Mechanics, Chinese Academy of Sciences, Beijing 100190, China
}

\section{A R T I C L E I N F O}

\section{Keywords:}

Top tensioned riser

Hydro-pneumatic tensioner

Mathematical model

Parameter analysis

\begin{abstract}
A B S T R A C T
In this paper an improved mathematical model of a hydro-pneumatic tensioner (HPT) system for top tensioned riser (TTR) is derived by consideration of friction, mass of piston and piston rod, tension loss in hydraulic oil piping, and compressibility of hydraulic oil. The vertical motion of the riser string is also considered. Subsequently, the proposed detailed model and the conventional simplified model are comparatively studied. Finally, the tension characteristic and performance parameters of the HPT are analyzed based on the proposed model. Results show that the conventional simplified model indeed overestimates the tension of tensioner as it neglects some performance parameters resulting in tension loss. The diameters of piston and piston rod and the initial pressure of high pressure (HP) gas have the most significant influence on the tension of the tensioner. The initial volume of HP gas and the initial pressure of low pressure (LP) gas also have some impact. The influence of the initial volume of LP gas and the inner diameter and length of the piping is relatively small. The research has some reference value for HPT and TTR design.
\end{abstract}

\section{Introduction}

Deep-sea oil-gas exploitation and production present many challenges, one of them being the design of technically feasible and cost effective riser systems [1]. TTR is one of the main configurations of riser systems, which has long been adopted to serve as the link between the floating production systems (FPSs) and the well head at the seabed for oil and gas transportation. In order to compensate the heave motion of FPS and prevent buckling of TTR due to its own weight, active and passive heave compensation devices or tensioner systems are equipped between FPS and TTR. Active heave compensation system is controlled by some local controllers to provide a desired force to the top of marine risers. Do [2-5] presented a constructive method to design a nonlinear controller for an active heave compensation system and designed a boundary controller for global stabilization of marine risers under environmental disturbances. On the contrary, passive tensioner system requires no active adjustment or controlled after the system is set nominally to achieve a certain tension factor, and to cover the expected range of stroke for a particular riser function (e.g., producing, water injection, completion/workover, or drilling) [67]. In this paper, we only study the passive tensioner systems.

Among the various tensioner systems, HPT systems have been recognized as a better tensioning means, which have been widely used in deep-sea oil-gas exploration and development. HPT systems are normally classified as a wireline riser tensioner (WRT) system or a direct-acting tensioner (DAT) system according to the existence of the wireline [8]. In the traditional TTR dynamic analysis process, HPT systems are commonly simulated as a constant vertical tension load or an equivalent linear spring or a simplified cylinder-piston system. Using a constant vertical tension load to simulate the top tension applied by the tensioning system, which ignores the tension variation caused by the FPS heave motion, is the simplest model. For example, Chang [9], Chen [10] and Mao [11] used the constant vertical tension load method in their forcing dynamic and vortex-induced vibration analysis process of TTR. Obviously, the constant vertical tension load method has some disadvantages. Firstly, it cannot reflect the variation of the applied top tension as FPS heaves. Secondly, the top tension is always applied in the vertical direction. To solve such a deficiency, a kind of equivalent linear spring model with a constant stiffness has been used to simulate the tensioner system [12-15]. In fact, the stiffness of tensioner is nonlinear and changes along the stroke variation. Therefore, a simplified cylinderpiston model has been further used to simulate the HPT system [8,16-18]. Yu [16] derived a simple tension formulation of a DAT system and used this equation to compute the tensioner stroke and riser

\footnotetext{
* Corresponding author at: State Key Laboratory of Hydraulic Engineering Simulation and Safety, Tianjin University, Tianjin 300350, China.

E-mail address: yang.yu@tju.edu.cn (Y. Yu).
} 
tension for $3000 \mathrm{ft}$ and $8000 \mathrm{ft}$ risers, but they neglected the effect of the LP gas and the mass of the piston. Yang [17] used the same tensioner model in their numerical model of TTRs with hydro-pneumatic tensioner for Spar application. Lee [8] simulated a WRT system dynamically to analyze the dynamic response of the platform and the riser string in an offshore drilling rig, but the effect of the LP gas, the mass of piston and the tension loss were neglected in the study. Pestana [18] proposed a more detailed nonlinear spring-damper model to represent a WRT system behavior for drilling during an emergency disconnection scenario, but the performance parameters of tensioner have not been indeep analyzed.

The coupling effect of the tensioner, riser and platform has become increasingly important, as the water depth increases and the tension and stroke of tensioner become larger. The performance of tensioner system is more significant and directly affects the dynamic response of TTR and the global motions of the platform. However, the simplified equivalent tensioner models neglecting some important factors cannot reflect the actual characteristics of the HPT system. The discrepancy between simulation and measurement calls for a model with rate dependent stiffness considering the compressibility of hydraulic oil, the interference of valve control and friction loss along piping or hose [19]. HPT is a complex structure containing a lot of key performance parameters, the study of which has a significance reference for the design process of tensioner and TTR. The objective of this study is to establish a relatively detailed nonlinear mathematical model of a HPT system and further research the effect of the performance parameters of tensioner on the tension of HPT. Finally, a basic tensioner design guideline for deep-sea oil and gas development projects is proposed based on the performance parameters analysis.

\section{Mathematical model}

\subsection{Structures of the tensioner system}

A DAT system shown in Fig. 1 is studied in this paper. The DAT system is a passive, direct acting system covering the expected range of stroke for a particular riser function. As shown in Fig. 1, the DAT system consists of numbers of hydraulic cylinders. The hydraulic cylinders are connected between the cassette frame and the TR. The cassette frame with guide rollers is mounted on the production deck of the platform. The rollers are used as centralizers to constrain the horizontal motion of the TTR. The tension of the DAT system is applied to the TTR through the TR.

The core component of the DAT system is a hydro-pneumatic system as shown in Fig. 2. The hydro-pneumatic system consists of a hydraulic cylinder containing a piston and a piston rod, a LP accumulator, a HP accumulator, and a hydraulic oil piping connecting the hydraulic cylinder and the HP accumulator. Fig. 3 shows the piston stroke process.

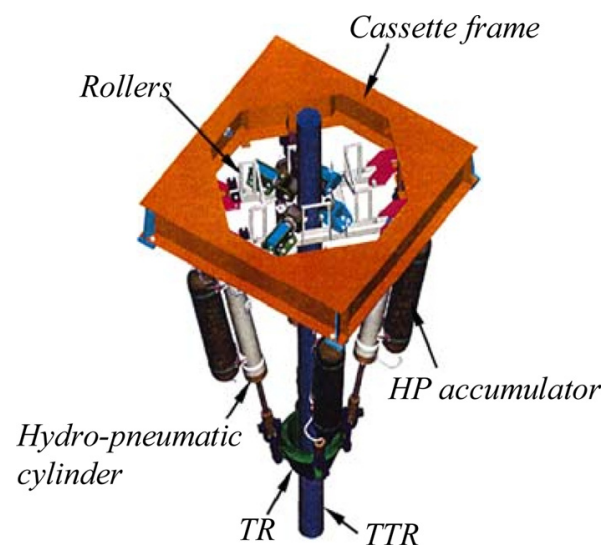

Fig. 1. Schematic of a DAT system.

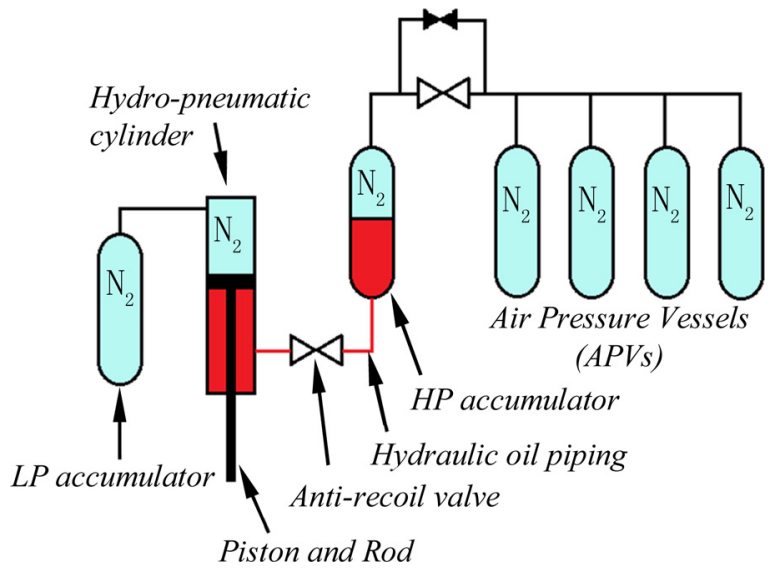

Fig. 2. Schematic of hydro-pneumatic system. (a) downstroke

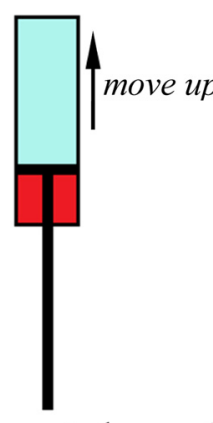

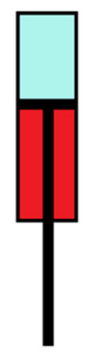

(b) midstroke

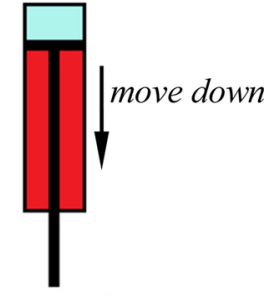

(c) upstroke
Fig. 3. Schematic of piston stroke.

Normally, the tensioner is on the midstroke state as shown in Fig. 3b. When the hydraulic cylinder moves up with the platform under wave load, the air in the HP accumulator is compressed and minimizes the vertical motion of the piston. This process is called piston downstroke as shown in Fig. 3a. When the platform and the hydraulic cylinder move down on the contrary, the air in the LP accumulator is compressed and the sustained high pressure of HP gas still limits the piston from moving down. This process is called piston upstroke as shown in Fig. 3c. As a result, the heave motion of the platform will not transmit directly to the TTR.

\subsection{Mathematical modeling of the hydro-pneumatic system}

The hydro-pneumatic system is a closed dynamic system. As the platform heaves, the pressures of HP and LP gas, the friction, and the hydraulic oil flowrate change dynamically, resulting in a dynamic variation of tension. The process of gas volume change is assumed adiabatic during the derivation.

\subsubsection{Hydraulic cylinder and LP accumulator}

Fig. 4 shows a force equilibrium diagram of the piston and piston rod assembly. According to the second Newton's law for the piston and piston rod, Eq. (1) is obtained:

$M \ddot{y_{p}}=-T+P_{o}\left(A_{p}-A_{r}\right)-P_{l} A_{p}-M g+F_{f}$

where, $M$ is the mass of piston and piston rod; $\ddot{y}_{p}$ is the acceleration of piston and piston rod; $T$ is the tension on the piston rod; $P_{o}$ is the pressure in the oil side chamber; $P_{l}$ is the pressure of the LP gas; $A_{p}$ is the piston area; $A_{r}$ is the cross section area of piston rod; $F_{f}$ is the friction force between the piston and the cylinder.

With the assumption that heat is not transferred during the operation in the LP accumulator, Eq. (2) is obtained: 


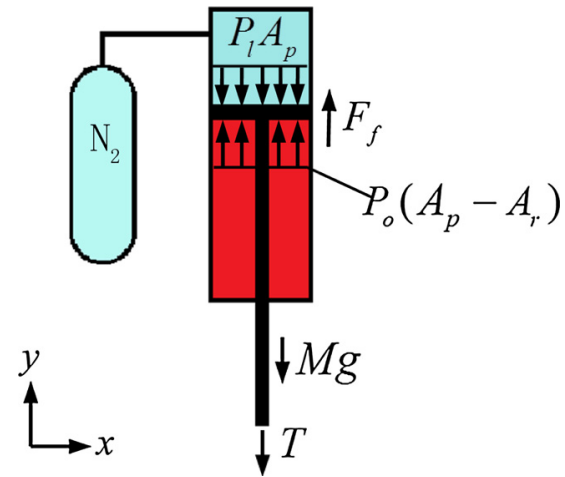

Fig. 4. Schematic of hydraulic cylinder.

$P_{l} V_{l}^{k}=P_{l 0} V_{l 0}^{k}$

where, $k$ is the gas constant; $V_{l}$ is the air volume during the operation; $P_{l o}$ is the initial air pressure; $V_{l o}$ is the initial air volume.

Therefore, the pressure in the blind side chamber during the operation can be written as follows:

$P_{l}=\frac{P_{l 0} V_{l 0}^{k}}{V_{l}^{k}}=\frac{P_{l 0} V_{l 0}^{k}}{\left(V_{l 0}-A_{p} s_{p}\right)^{k}}$

where, $s_{p}=y_{p}-y_{c}$ is the piston stroke; $y_{p}$ is the piston displacement; $y_{c}$ is the cylinder (or platform) displacement.

As the cylinder heaves relative to the piston, the corresponding friction force between them has an influence on the tension of the tensioner. The knowledge of the friction force in the tensioner is important to obtain the accurate tension during the simulation. The Stribeck friction occurs when liquid or solid oil contact with the surface of a moving mechanical device [8]. In this study, the Stribeck friction model $[8,19,20]$ shown in Eq. (4) is used to calculate the friction force.

$F_{f}=\left[F_{c}+\left(F_{s}-F_{c}\right) \exp \left(-\frac{\left|\dot{s}_{p}\right|}{v_{s}}\right)\right] \operatorname{sign}\left(-\dot{s}_{p}\right)-k_{v} \dot{s}_{p}$

where, $F_{c}$ is the Coulomb friction force; $F_{s}$ is the static friction force; $\dot{s}_{p}=\dot{y}_{p}-\dot{y}_{c}$ is piston stroke velocity; $\dot{y}_{p}$ is the piston velocity; $\dot{y}_{c}$ is the cylinder velocity; $v_{s}$ is the limit velocity (Stribeck velocity); $k_{v}$ the viscous friction coefficient.

\subsubsection{HP accumulator}

Fig. 5 shows a force equilibrium diagram of the piston in the HP accumulator. According to the second Newton's law for the piston, Eq. (5) is also obtained:

$m a_{a}=-P_{o a} A_{a}+P_{h} A_{a}+m g+F_{f a}$

where, $m$ is the piston mass; $a_{a}$ is the accelerated velocity of the piston; $P_{o a}$ is the pressure in the oil side chamber; $P_{h}$ is the pressure of HP gas; $A_{a}$ is the piston area; $F_{f a}$ is the friction force.

In a similar way as the Eqs. (2) and (3), the HP air pressure during the operation can be obtained as follows:

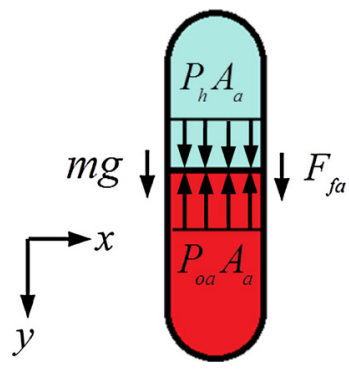

Fig. 5. Schematic of HP accumulator.

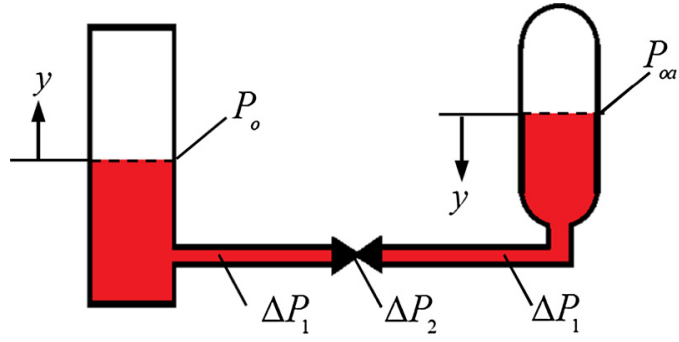

Fig. 6. Tension loss in the hydraulic oil piping.

$P_{h}=\frac{P_{h 0} V_{h 0}^{k}}{V_{h}^{k}}=\frac{P_{h 0} V_{h 0}^{k}}{\left(V_{h 0}+A_{a} s_{a}\right)^{k}}$

where, $V_{h}$ is the air volume during the operation; $P_{h o}$ is the initial air pressure; $V_{h o}$ is the initial air volume; $s_{a}$ is the piston displacement relative to the accumulator.

The Stribeck friction model $[8,19,20]$ is also used to calculate the friction between the piston and the HP accumulator as follows:

$F_{f a}=\left[F_{c a}+\left(F_{s a}-F_{c a}\right) \exp \left(-\frac{\left|\dot{s}_{a}\right|}{v_{s}}\right)\right] \operatorname{sign}\left(-\dot{S}_{a}\right)-k_{v} \dot{s}_{a}$

where, $F_{c a}$ is the Coulomb friction force; $F_{s a}$ is the static friction force; $\dot{s}_{a}$ is the piston velocity relative to the accumulator.

\subsubsection{Tension loss in the hydraulic oil piping}

When hydraulic oil flows through the piping (including hoses) and valves, a certain amount of energy of the hydraulic oil will be dissipated because of fluid viscosity, as a result of which, the oil pressures in the hydraulic cylinder $P_{o}$ and in the HP accumulator $P_{o a}$ are different as shown in Fig. 6. The pressure loss due to hydraulic oil flow is reasonably divided into two parts, i.e. the pressure loss along the piping $\Delta P_{1}$ and across the anti-recoil valve $\Delta P_{2}$. The pressure loss in the hydraulic oil piping depends on factors including hydraulic oil viscosity, flow speed, section size of piping, valve closure and so on.

For water based hydraulic fluids, the water glycol fluids contain $35 \%-45 \%$ of water with typical Newtonian rheology, while other hydraulic fluids may demonstrate Herschel-Bulkley, Cross, Carreau or Power-Law rheology [19]. The hydraulic oil with Newtonian rheology is considered in this paper. Besides, some sections of the piping may use hoses instead of steel pipes to absorb some shock loads. In this paper, the deformation of the hoses is neglected and the inner diameters of steel pipes and hoses are assumed to be identical. Therefore, the pressure loss along the piping (including hoses) is calculated by the DarcyWeisbach equation as follows [21]:

$\Delta P_{1}=\frac{\lambda\left(l+l_{e q}\right)}{d} \cdot \frac{\rho v^{2}}{2}$

where, $\lambda$ is the Darcy-Weisbach friction factor depending on the flow conditions and the flow is assumed laminar in this paper; $l$ is the geometrical length of piping (including hoses); $l_{e q}$ is the equivalent length of pressure loss accounting for the local resistances, such as ports, Yshape connectors, bends, inlet and outlet losses, and so on; $d$ is the inner diameter of piping (including hoses); $\rho$ is the density of hydraulic oil; $v$ is the flow velocity of hydraulic oil.

The pressure loss across the anti-recoil valve is calculated by the following equation $[18,19]$ :

$\Delta P_{2}=\frac{\pi^{2} d^{4}}{8 C_{v}^{2}} \cdot \frac{\rho v^{2}}{2}$

where, $C_{v}$ is the anti-recoil valve flow coefficient which is a function of valve opening.

Compounding the pressure loss along the hydraulic piping $\Delta P_{1}$ and across the anti-recoil valve $\Delta P_{2}$, the total pressure loss is obtained as follows: 


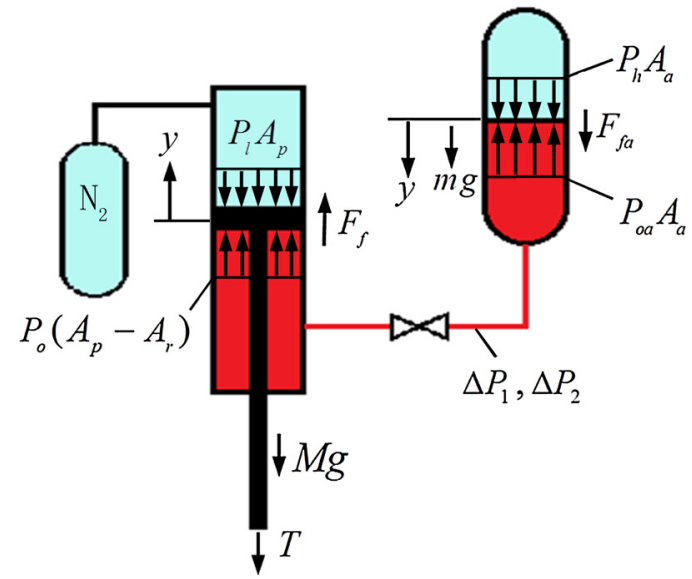

Fig. 7. Schematic of the hydro-pneumatic system.

$P_{o a}-P_{o}=\frac{\rho}{2}\left(\frac{\lambda l}{d}+\frac{\lambda l_{e q}}{d}+\frac{\pi^{2} d^{4}}{8 C_{v}^{2}}\right) v|v|$

If the oil pressure in the hydraulic cylinder $P_{o}$ becomes higher than the pressure in the HP accumulator $P_{o a}$, the hydraulic oil enters the accumulator chamber and compresses the HP gas, thus storing hydropneumatic energy. On the other hand, a drop in the fluid pressure $P_{o}$ during piston upstroke motion restores the hydraulic oil back into the cylinder.

\subsubsection{The whole hydro-pneumatic system}

Fig. 7 shows a schematic of the whole hydro-pneumatic system. Considering the compressibility of hydraulic oil, the pressure variation $\Delta P_{o}$ and the volume variation $\Delta V_{o}$ follows the following relationship:

$\Delta P_{o}=-K \frac{\Delta V_{o}}{V_{o 0}}$

where, $K$ is the bulk modulus of elasticity; $V_{o O}$ is the initial volume of the hydraulic oil.

As the bulk modulus of elasticity of hydraulic oil is relatively large and the volume variation $\Delta V_{o}$ is small, an approximate expression rather than a tedious derivation for the compressed volume of the hydraulic oil is introduced:

$\Delta V_{o}=-\frac{V_{o 0}}{K} \Delta P_{o} \approx-\frac{V_{o 0}}{K}\left[\frac{P_{h 0} V_{h 0}^{k}}{\left[V_{h 0}+\left(A_{p}-A_{r}\right) s_{p}\right]^{k}}-P_{h 0}\right]$

where, $\Delta P_{o} \approx \frac{P_{h 0} V_{h 0}^{k}}{\left[V_{h 0}+\left(A_{p}-A_{r}\right) s_{p}\right]^{k}}-P_{h 0}$, which is simplified from Eq. (6) by assuming $\left(A_{p}-A_{r}\right) s_{p}=A_{a} s_{a}$.

When the piston retracts and extracts, the piston stroke direction and the oil flow direction in the piping may be out of phase. Therefore, a time lag $\Delta t$ is considered for the oil flow in the piping. By assuming the oil volume $Q$ flowing into or out of the piping and the HP accumulator is equal, an approximate expression of oil volume $Q$ is shown as follows:

$Q=A_{a} s_{a}=\left(A_{p}-A_{r}\right) \cdot s_{p}(t-\Delta t)-\Delta V_{o}$

The flow rate $\dot{Q}$ in the piping is also approximately expressed with the time lag $\Delta t$ :

$\dot{Q}=A v=A_{a} \dot{s}_{a}=\left(A_{p}-A_{r}\right) \cdot \dot{s}_{p}(t-\Delta t)-\frac{d \Delta V_{o}}{d t}$

where, $A$ is the cross section area of the piping.

Integrating Eqs. (1), (3), (5), (6), and (10), the mathematical model of the hydro-pneumatic system is obtained as follows.
$\left\{\begin{array}{l}T=P_{o}\left(A_{p}-A_{r}\right)-P_{l} A_{p}-M g-M \ddot{y}_{p}+F_{f} \\ m a_{a}=-P_{o a} A_{a}+P_{h} A_{a}+m g+F_{f a} \\ P_{o a}-P_{o}=\frac{\rho}{2}\left(\frac{\lambda l}{d}+\frac{\lambda l_{e q}}{d}+\frac{\pi^{2} d^{4}}{8 C_{v}^{2}}\right) v|v| \\ P_{l}=\frac{P_{l 0} V_{l 0}^{k}}{\left(V_{l 0}-A_{p} s_{p}\right)^{k}} \\ P_{h}=\frac{P_{h 0} V_{h 0}^{k}}{\left[V_{h 0}+A_{a} s_{a}\right]^{k}}\end{array}\right.$

As is shown in Eq. (15), the tension $T$ is a function of the piston stroke $s_{p}$, the piston stroke velocity $\dot{s}_{p}$, the piston stroke acceleration $\ddot{s}_{p}$, and the acceleration of piston and piston rod $\ddot{y}_{p}$.

\subsection{Simplified model of the hydro-pneumatic system}

Neglecting the compressibility of hydraulic oil, the pressure of the LP gas, the mass of piston and piston rod in the hydraulic cylinder, the tension loss in the hydraulic oil piping, and the piston mass and friction in the HP accumulator, Eq. (15) will be reduced to the following equation:

$T=\frac{P_{h 0} V_{h 0}^{k}\left(A_{p}-A_{r}\right)}{\left[V_{h 0}+\left(A_{p}-A_{r}\right) S_{p}\right]^{k}}+F_{f}$

Let $L_{0}=V_{h 0} /\left(A_{p}-A_{r}\right), T_{0}=P_{h 0}\left(A_{p}-A_{r}\right)$ and substituting them into Eq. (16) leads to the simplified model:

$T=T_{0}\left(\frac{L_{0}}{L_{0}+s_{p}}\right)^{k}+F_{f}$

Eq. (17) is the same with the derived equation in [16,17], which is widely used in the engineering.

\subsection{Mathematical modeling of the riser string}

Assuming that the riser string is an elastic body with a lumped mass on the top, the simplified riser string model is shown in Fig. 8. The top tension is applied on the TR. The lumped mass $\bar{m}$ representatives the structure mass above the TR. The damping coefficient of the riser string is $c_{\text {riser }}$. The spring coefficient $k_{\text {riser }}$ that indicates the riser string stiffness can be calculated as follows [8].

$k_{\text {riser }}=\frac{E_{\text {riser }} A_{\text {riser }}}{L_{\text {riser }}}$

where, $E_{\text {riser }}, A_{\text {riser }}, L_{\text {riser }}$ are the elastic modulus, section area, and riser length below the TR respectively.

The motion equation of the lumped mass is shown as follows.

$\bar{m} \ddot{y}_{p}+c_{r i s e r} \dot{y}_{p}+k_{\text {riser }}\left(y_{p 0}+y_{p}\right)=N T \cos \theta-\bar{m} g$

where, $y_{p 0}=\left(N T_{0} \cos \theta-\bar{m} g\right) / k_{\text {riser }}$ is the initial elongation of the riser string; $N$ is the number of the cylinders; $\theta$ is the angle between the cylinders and the TTR.

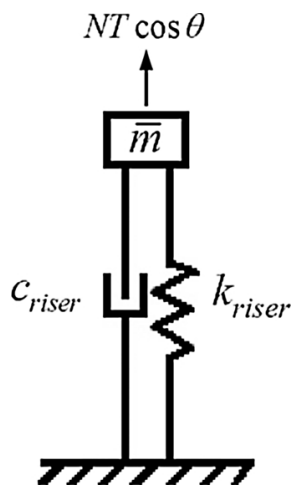

Fig. 8. Simplified riser string model. 
Table 1

Structure parameters of the tensioner system.

\begin{tabular}{lll}
\hline Component & parameter & Value \\
\hline Hydraulic cylinder & Piston diameter & $0.56 \mathrm{~m}$ \\
& Piston rod diameter & $0.23 \mathrm{~m}$ \\
& Initial oil volume & $1.23 \mathrm{~m}^{3}$ \\
& Piston and rod mass & $500 \mathrm{~kg}$ \\
LP accumulator & Initial gas pressure & $0.1 \mathrm{MPa}$ \\
& Initial gas volume & $1.25 \mathrm{~m}^{3}$ \\
HP accumulator & Initial gas pressure & $2.8 \mathrm{MPa}$ \\
& Initial gas volume & $2.68 \mathrm{~m}^{3}$ \\
& Piston diameter & $0.6 \mathrm{~m}$ \\
Hydraulic oil piping & Piston mass & $25 \mathrm{~kg}$ \\
& Geometrical length & $6 \mathrm{~m}$ \\
& Equivalent length & $4 \mathrm{~m}$ \\
& Inner diameter & $0.16 \mathrm{~m}$ \\
\hline
\end{tabular}

\section{Comparison of the proposed detailed model and simplified} model

This section compares the proposed mathematical model with the conventional simplified model normally used in the engineering. The tensioner system contains four cylinders and the structure parameters of each hydro-pneumatic system are shown in Table 1 . The angle between the cylinders and TTR is $12^{\circ}$. The length, outer diameter, and inner diameter of riser string are $1000 \mathrm{~m}, 0.27 \mathrm{~m}$, and $0.24 \mathrm{~m}$ respectively. The lumped mass on the riser top is $8554.63 \mathrm{~kg}$. The relevant coefficients used during the solution procedure are listed in Table 2.

As an example, the hydraulic cylinder (or platform) heaves harmonically with an amplitude of $2 \mathrm{~m}$ and a period of $12 \mathrm{~s}$. Fig. 9 shows the piston motion and stroke time history of the two models. Because of the relatively large stiffness of the riser string, the piston motions are relatively small and the piston strokes of the two models are almost the same. The vertical tensions of the two models are shown in Fig. 10. The tension of the simplified model is larger than that of the detailed model especially when the piston moves from downstroke to upstroke. In this example, the tension of the simplified model is about $85.53 \mathrm{kN}(3.17 \%)$ larger than that of the detailed model at the peak of downstroke area, and it is about $203.51 \mathrm{kN}(12.54 \%)$ larger at the peak of upstroke area. Therefore, the simplified model indeed overestimates the tension of the tensioner as it neglects some key performance parameters resulting in tension loss including the pressure of the LP gas, the mass of piston and piston rod in the hydraulic cylinder, the tension loss in the hydraulic oil piping, and the piston mass and friction in the HP accumulator.

\section{Tension components of the tensioner}

According to the tension calculation formulation

Table 2

Calculation coefficients.

\begin{tabular}{ll}
\hline parameter & Value \\
\hline Gas constant, $k$ & 1.3 \\
Stribeck velocity, $v_{s}$ & $0.1 \mathrm{~m} / \mathrm{s}$ \\
Viscous friction coefficient, $k_{v}$ & $5000 \mathrm{~N} /(\mathrm{m} / \mathrm{s})$ \\
Coulomb friction force, $F_{s}=3 \% T_{o}$ & $16.32 \mathrm{kN}$ \\
Static friction force, $F_{c}=2 \% T_{o}$ & $10.88 \mathrm{kN}$ \\
Coulomb friction force, $F_{s a}=0.3 \% T_{o}$ & $1.63 \mathrm{kN}$ \\
Static friction force, $F_{c a}=0.2 \% T_{o}$ & $1.09 \mathrm{kN}$ \\
Reynolds number, $R_{e}$ & 2000 \\
Darcy-Weisbach friction factor, $\lambda=75 / R_{e}$ & 0.0375 \\
Anti-recoil valve flow coefficient, $C_{v}$ & 0.5 \\
Density of hydraulic oil, $\rho$ & $900 \mathrm{~kg} / \mathrm{m}^{3}$ \\
Bulk modulus of elasticity, $K$ & $700 \mathrm{MPa}$ \\
Time lag of oil flow, $\Delta t$ & $0.12 \mathrm{~s}$ \\
Elastic modulus of riser, $E_{\text {riser }}$ & $210 \mathrm{GPa}$ \\
Damping coefficient of riser, $c_{r i s e r}$ & 0.05 \\
\hline
\end{tabular}

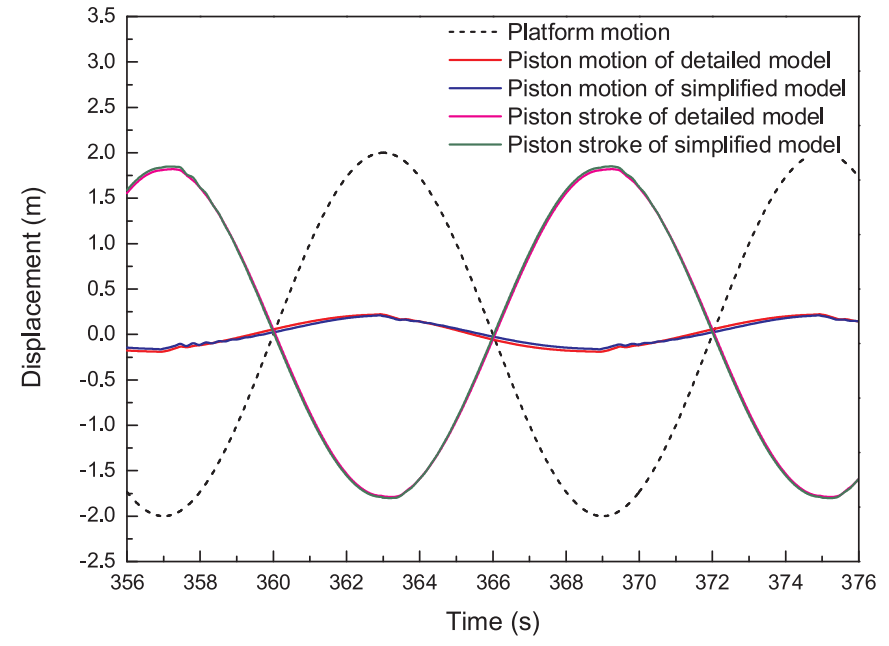

Fig. 9. Piston motion and stroke of the two models.

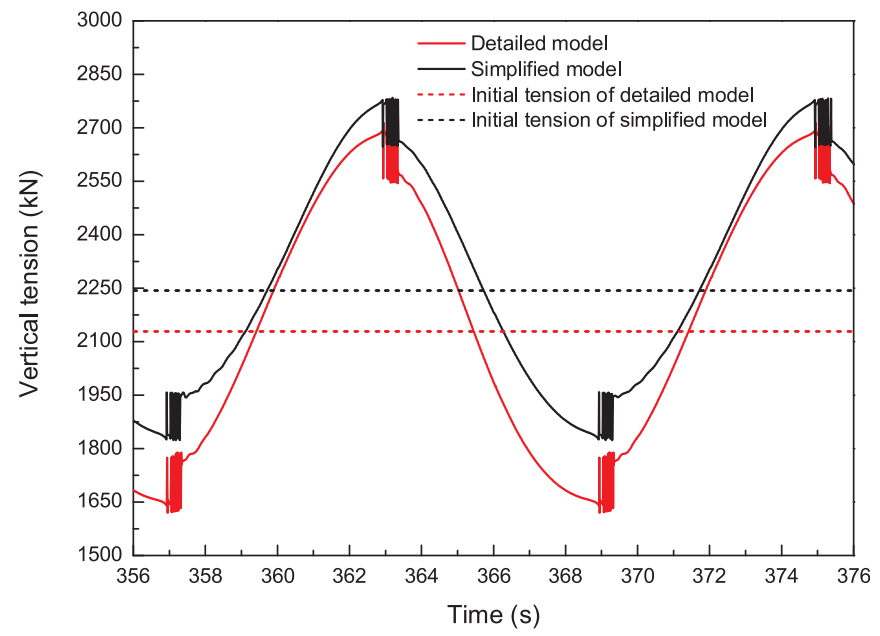

Fig. 10. Vertical tensions of the two models.

$T=P_{o}\left(A_{p}-A_{r}\right)-P_{l} A_{p}-M g-M \ddot{y}_{p}+F_{f}$ in Eq. (15), the tension of tensioner is directly affected by the parameters including the pressure in the rod side chamber $P_{o}\left(A_{p}-A_{r}\right)$, the pressure in the blind side chamber $P_{l} A_{p}$, the gravity of piston and piston rod $M g$, the inertia force of piston and piston rod $M \ddot{y}_{p}$, and the friction $F_{f}$.

Fig. 11 shows the variation curves of the tension of the tensioner and the tension components. The pressure in the rod side chamber is close to the tension of the tensioner and is much larger than other components. However, it can be seen from Fig. 11 that difference exists between the tension of the tensioner and the pressure in the rod side chamber especially when the piston moves from downstroke to upstroke. In this example, the pressure in the rod side chamber is about $69.11 \mathrm{kN}(16.68 \%)$ larger than the tension of the tensioner at the peak of the upstroke area. Except for the pressure in the rod side chamber, other tension components are ordered by the pressure in the blind side chamber, the friction, the gravity of piston and piston rod, and the inertia force of piston and piston rod. As shown in Fig. 11, the sign of the friction force is reversed almost at the same time as the stroke velocity reversal, which leads to an obvious break of the tension when the stroke velocity reverses.

Fig. 12 shows the pressure variation curves of different interfaces. The pressures at the two sides of HP accumulator are almost the same, which illustrates the influence of the piston mass and the friction in the HP accumulator is small. The pressure at the rod side of hydraulic cylinder and the pressure at the oil side of HP accumulator have an alternating size delays. The difference of them is caused by the pressure 

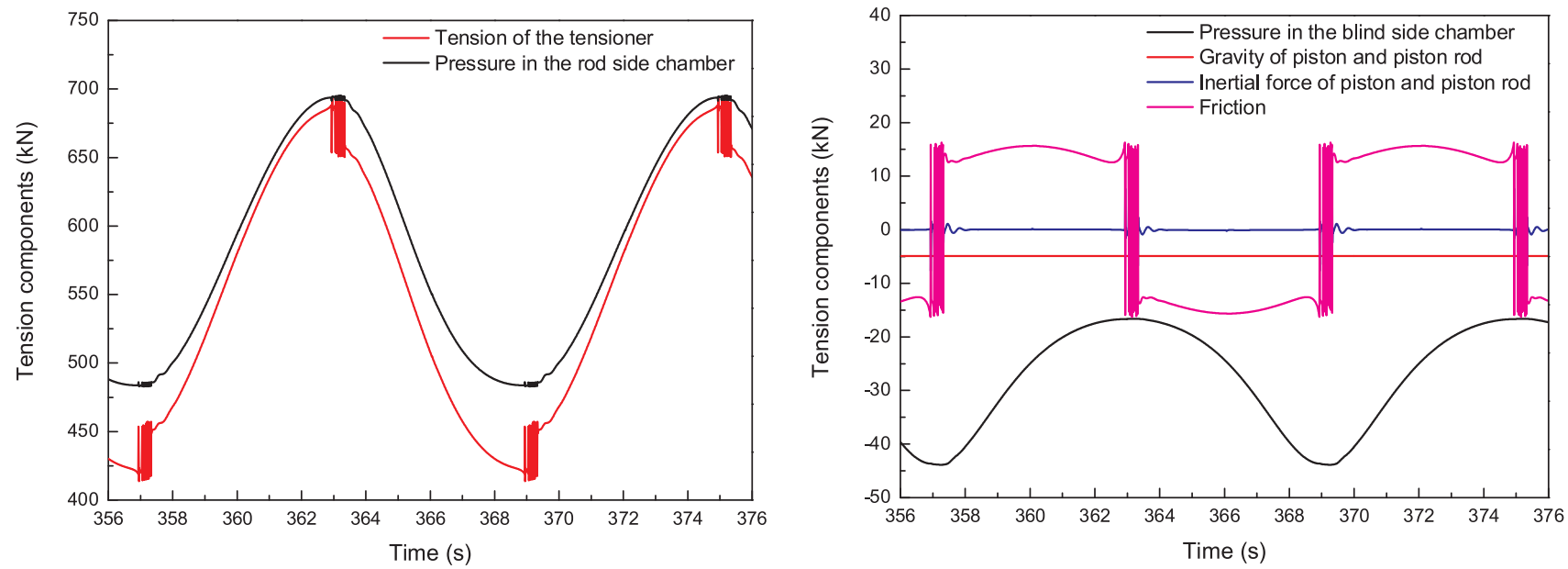

Fig. 11. Tension components.

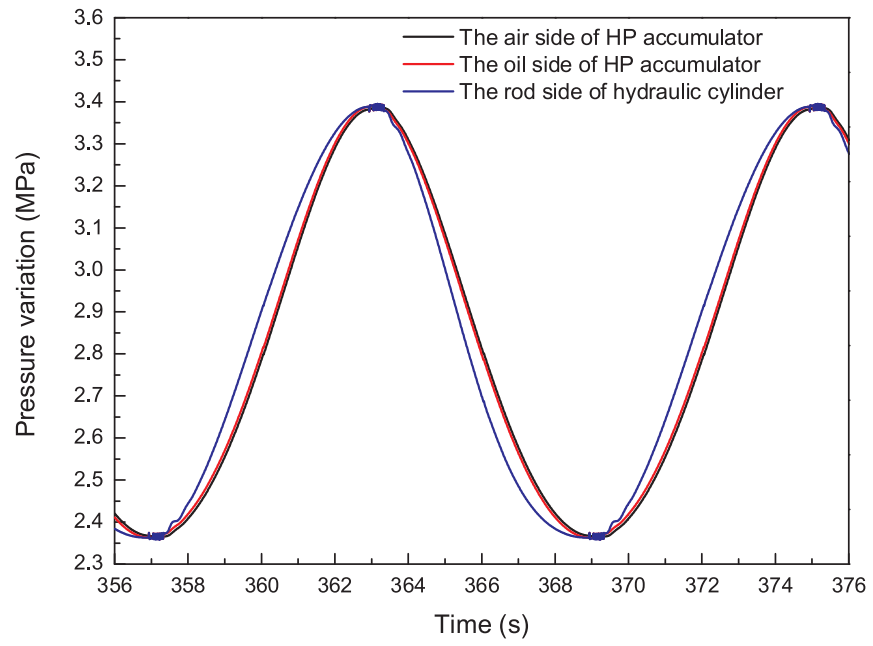

Fig. 12. Pressure variation of different interfaces.

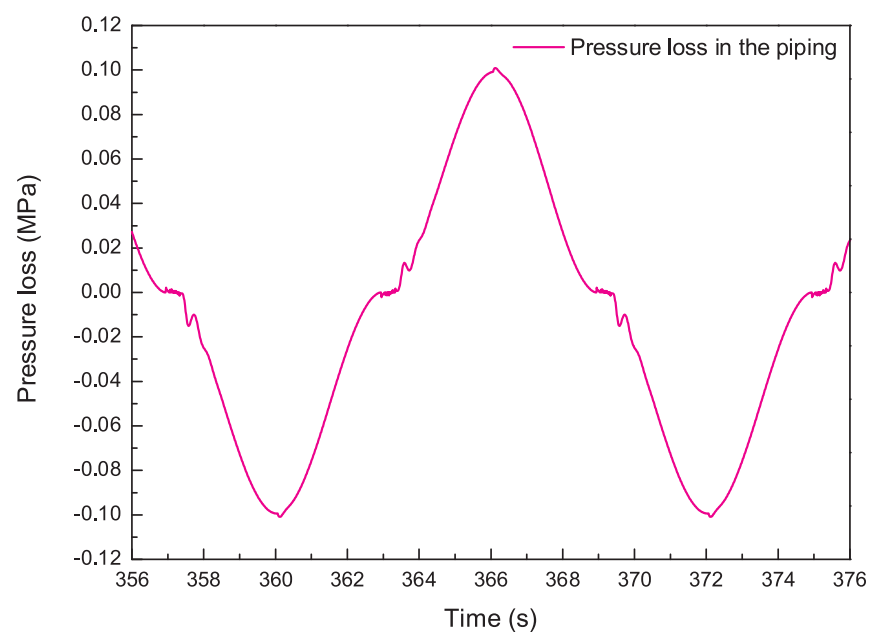

Fig. 13. Pressure loss in the piping.

loss in the piping shown in Fig. 13.

\section{Performance parameters analysis}

In order to fully grasp the mechanical behavior of HPT, it is necessary to study how the performance parameters of the hydro-

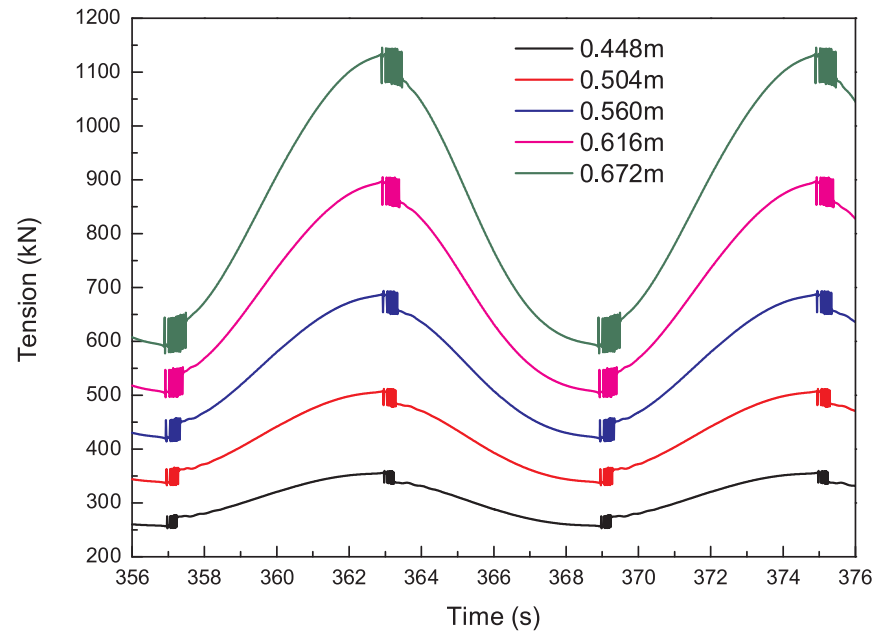

Fig. 14. Tension with different piston diameters.

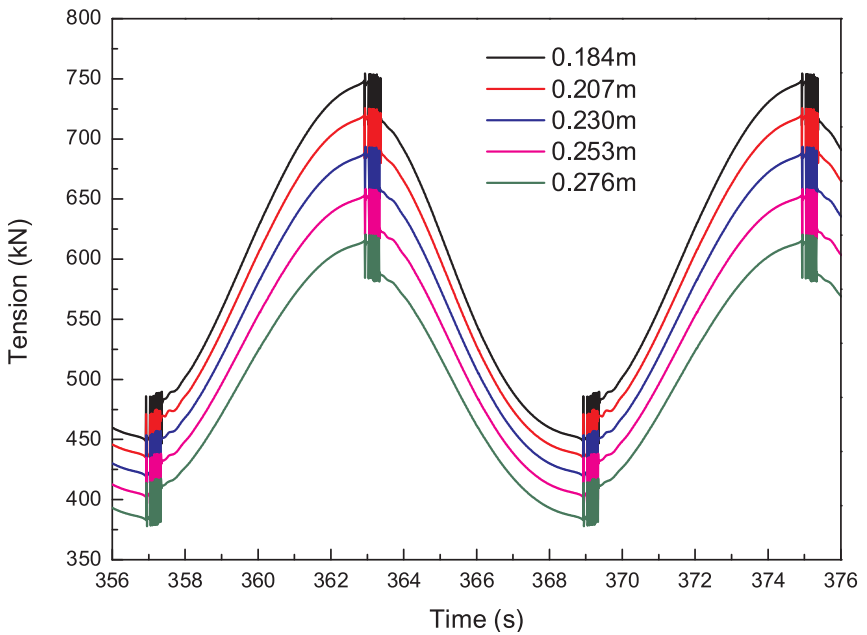

Fig. 15. Tension with different piston rod diameters.

pneumatic system affect the tension of tensioner.

\subsection{Diameters of piston and piston rod}

Keeping the diameter of the piston rod $0.23 \mathrm{~m}$ unchanged, five kinds of piston diameters $(0.448 \mathrm{~m}, 0.504 \mathrm{~m}, 0.56 \mathrm{~m}, 0.616 \mathrm{~m}$ and $0.672 \mathrm{~m})$ 


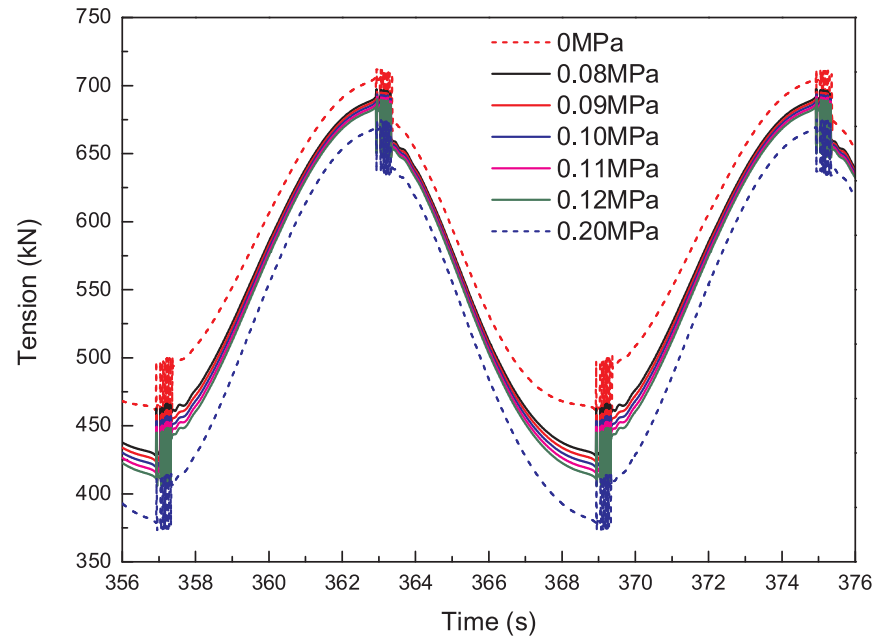

Fig. 16. Tension with different initial pressures.

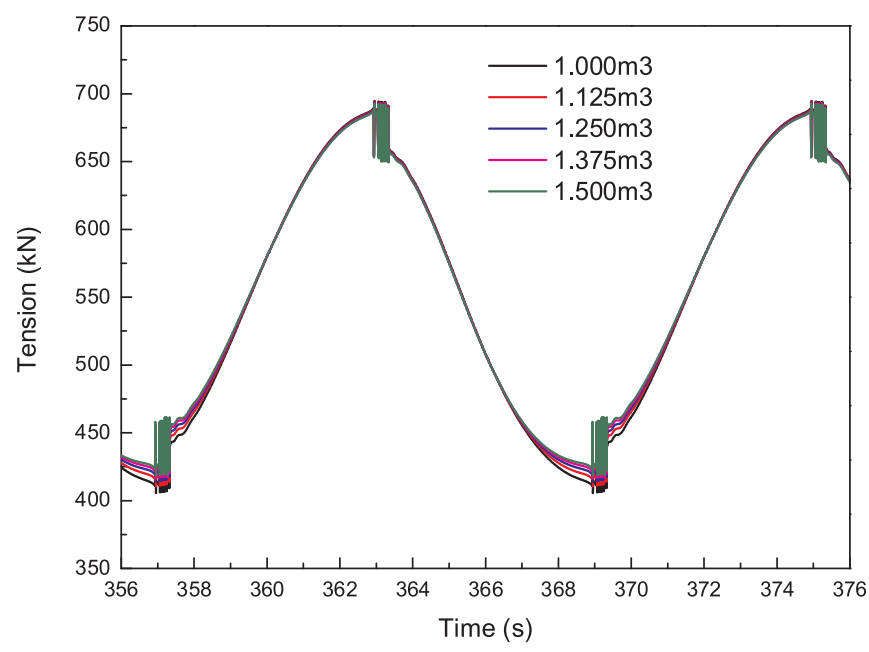

Fig. 17. Tension with different initial volumes.

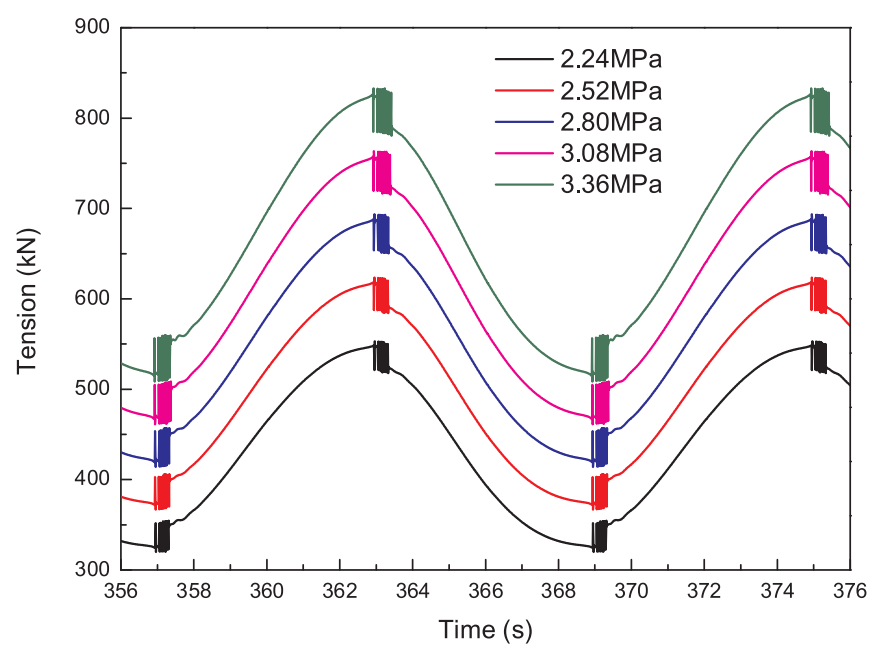

Fig. 18. Tension with different initial pressures.

with a variation gradient of $0.056 \mathrm{~m}$ (i.e. $10 \%$ of $0.56 \mathrm{~m}$ ) are selected to be the calculation variables and the comparison results are shown in Fig. 14. The tension size and amplitude increases significantly as the piston diameter becomes larger. Make the tension of $0.56 \mathrm{~m}$ be the reference quantity. In this example, the maximum tensions from

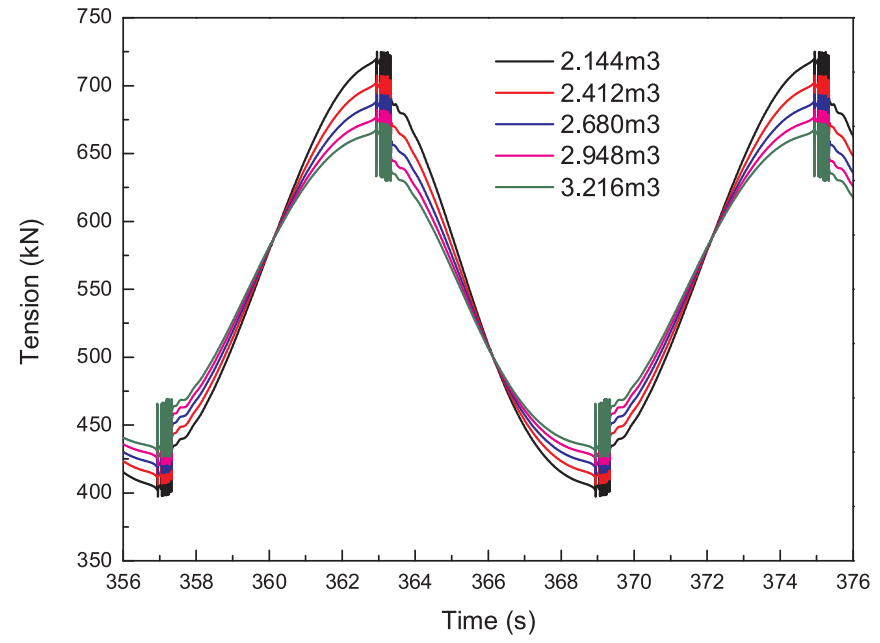

Fig. 19. Tension with different initial volumes.

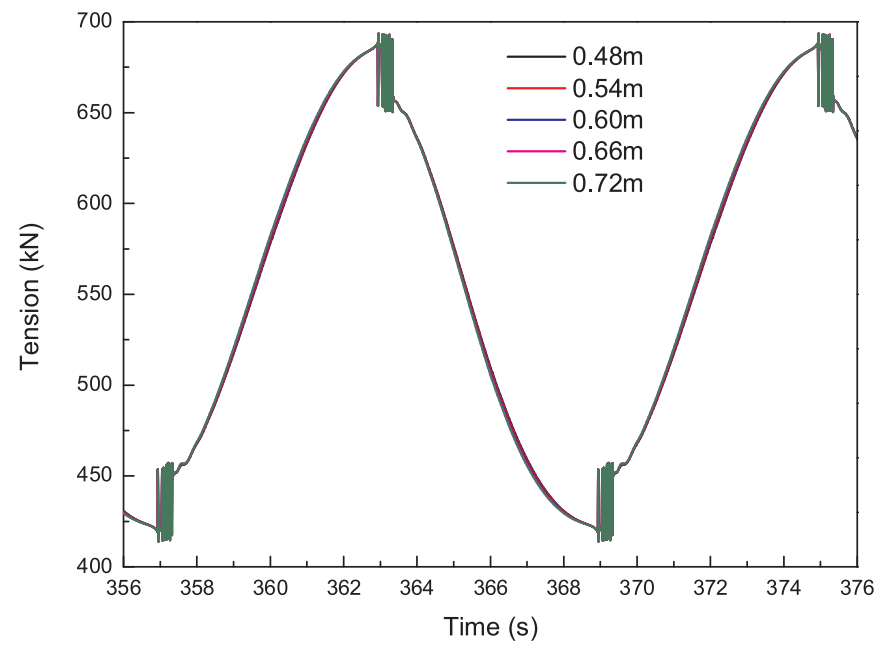

Fig. 20. Tension with different piping lengths.

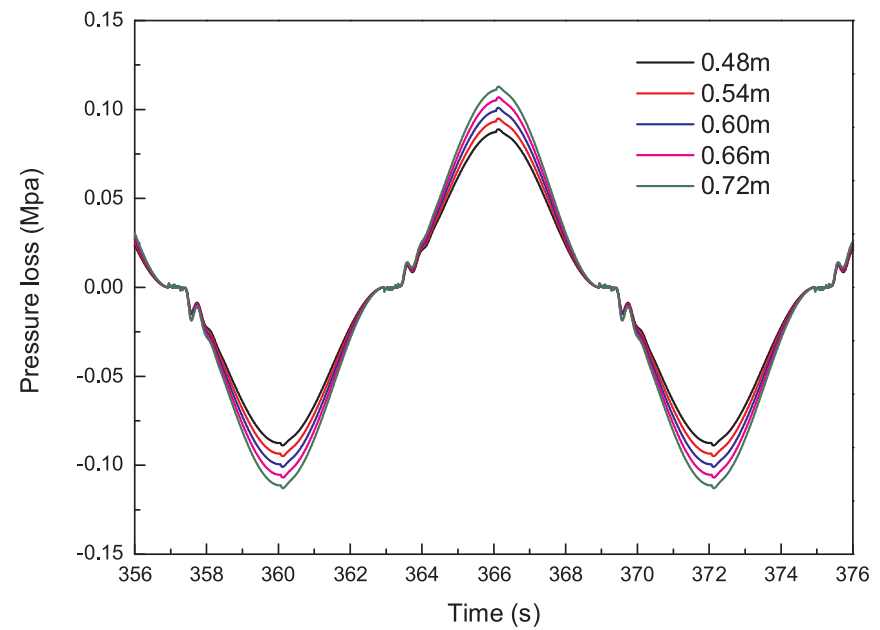

Fig. 21. Pressure loss with different piping lengths.

$0.448 \mathrm{~m}$ to $0.672 \mathrm{~m}$ are about $51.34 \%, 69.44 \%, 100 \%, 129.11 \%$, and $163.13 \%$ of that of $0.56 \mathrm{~m}$, while the minimum tensions are about $61.95 \%, 87.70 \%, 100 \%, 122.16 \%$ and $143.16 \%$ of that of $0.56 \mathrm{~m}$.

Keeping the diameter of the piston $0.56 \mathrm{~m}$ unchanged, five kinds of piston rod diameters $(0.184 \mathrm{~m}, 0.207 \mathrm{~m}, 0.23 \mathrm{~m}, 0.253 \mathrm{~m}$ and $0.276 \mathrm{~m})$ 


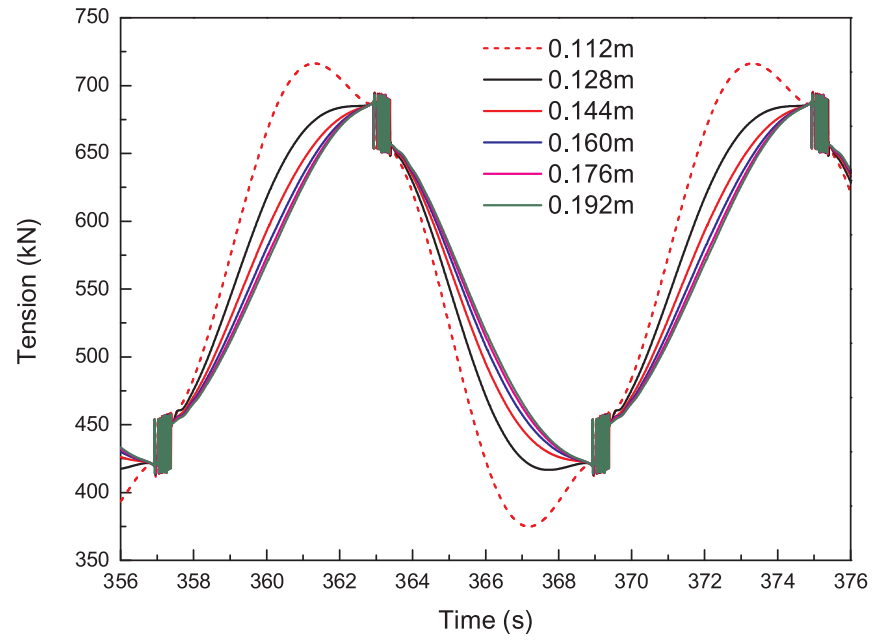

Fig. 22. Tension with different inner diameters.

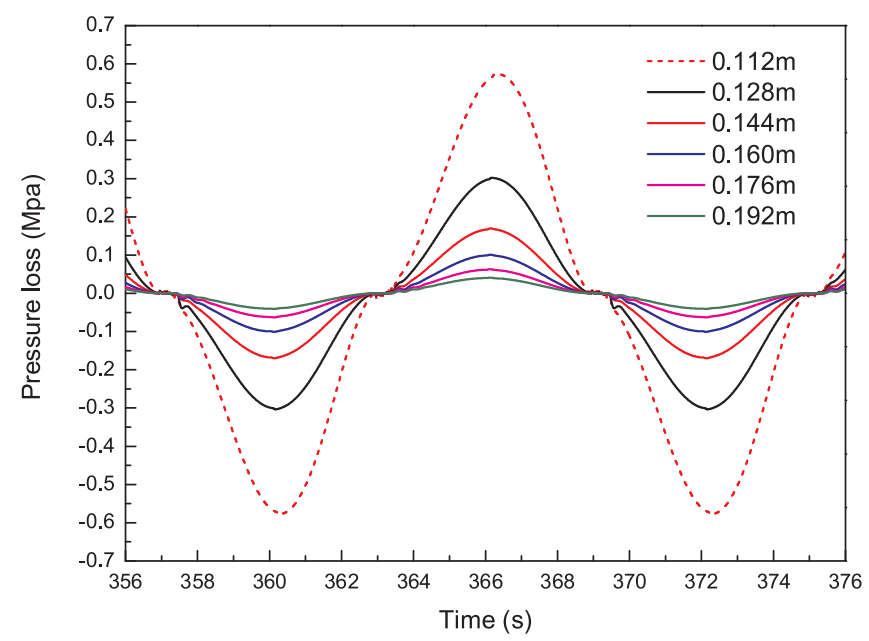

Fig. 23. Pressure loss with different inner diameters.

with a variation gradient of $0.023 \mathrm{~m}$ (i.e. $10 \%$ of $0.23 \mathrm{~m}$ ) are selected to be the calculation variables and the comparison results are shown in Fig. 15. The tension size and amplitude decreases as the piston rod diameter becomes larger. The tension of $0.23 \mathrm{~m}$ is also set to be the reference quantity. The maximum tensions from $0.184 \mathrm{~m}$ to $0.276 \mathrm{~m}$ are about $107.32 \%, 103.21 \%, 100 \%, 94.94 \%$, and $89.45 \%$ of that of $0.23 \mathrm{~m}$, while the minimum tensions are about $109.44 \%, 106.07 \%$, $100 \%, 95.87 \%$ and $91.31 \%$ of that of $0.23 \mathrm{~m}$.

Accordingly, the diameters of piston and piston rod are both key parameters that influence greatly on the tension of tensioner, besides the diameter of piston has a relatively greater impact.

\subsection{Initial pressure and volume of LP gas}

Five kinds of initial pressures $(0.08 \mathrm{MPa}, 0.09 \mathrm{MPa}, \quad 0.1 \mathrm{MPa}$, $0.11 \mathrm{MPa}$ and $0.12 \mathrm{MPa}$ respectively) with a variation gradient of $0.01 \mathrm{MPa}$ (i.e. $10 \%$ of $0.1 \mathrm{MPa}$ ) are selected to be the calculation variables, in addition $0 \mathrm{MPa}$ (neglecting the effect of LP gas) and $0.2 \mathrm{MPa}(200 \%$ of $0.1 \mathrm{MPa})$ are also considered for a more thorough comparison. As shown in Fig. 16, the tension of tensioner decreases as the initial pressure of LP gas becomes larger. It also shows that the differences of the tensions at upstroke area are bigger than that at downstroke area. In this example, the maximum tensions from $0 \mathrm{MPa}$ to $0.2 \mathrm{MPa}$ are about $101.25 \%, 100.53 \%, 100.26 \%, 100 \%, 99.73 \%$, $99.47 \%$ and $97.34 \%$ of that of $0.1 \mathrm{MPa}$, while the minimum tensions are about $112.42 \%, 104.28 \%, 101.00 \%, 100 \%, 99.01 \%, 98.01 \%$ and $90.14 \%$ of that of $0.1 \mathrm{MPa}$.

The comparison results with different initial volumes $\left(1 \mathrm{~m}^{3}\right.$, $1.125 \mathrm{~m}^{3}, 1.25 \mathrm{~m}^{3}, 1.375 \mathrm{~m}^{3}$ and $1.50 \mathrm{~m}^{3}$ respectively) with a variation gradient of $0.125 \mathrm{~m}^{3}$ (i.e. $10 \%$ of $1.25 \mathrm{~m}^{3}$ ) are shown in Fig. 17. It shows the initial volume of the LP gas has a relatively small impact of the tension of tensioner. As the initial volume of LP gas becomes larger, there is only a small increment at upstroke area, while the tensions at downstroke area are almost the same.

Accordingly, the initial pressure of the LP gas has an impact on the tension of tensioner, while the influence of initial volume is relative small. Some conventional studies neglecting the effect of LP gas $[8,16,17]$ cannot actually reflect the tension of tensioner. Therefore, it is recommended to consider the effect of LP gas in the tension calculation of tensioner.

\subsection{Initial pressure and volume of HP gas}

The comparison results with different initial pressures $(2.24 \mathrm{MPa}$, 2.52 MPa, 2.8 MPa, 3.08 MPa and $3.36 \mathrm{MPa}$ respectively) with a variation gradient of $0.28 \mathrm{MPa}$ (i.e. $10 \%$ of $2.8 \mathrm{MPa}$ ) are shown in Fig. 18. The tension of tensioner increases significantly as the initial pressure of HP gas becomes larger. The maximum tensions from $2.24 \mathrm{MPa}$ to $3.36 \mathrm{MPa}$ are about $75.15 \%, 89.91 \%, 100 \%, 108.58 \%$ and $118.83 \%$ of that of $2.8 \mathrm{MPa}$, while the minimum tensions are about $85.00 \%$, $88.61 \%, 100 \%, 113.89 \%$ and $124.97 \%$ of that of $2.8 \mathrm{MPa}$.

The comparison results with different initial volumes $\left(2.144 \mathrm{~m}^{3}\right.$, $2.412 \mathrm{~m}^{3}, 2.68 \mathrm{~m}^{3}, 2.948 \mathrm{~m}^{3}$ and $3.216 \mathrm{~m}^{3}$ respectively) with a variation gradient of $0.268 \mathrm{~m}^{3}$ (i.e. $10 \%$ of $2.68 \mathrm{~m}^{3}$ ) are shown in Fig. 19 . The tension of tensioner decreases as the initial volume increases when the piston is at downstroke area, but it is just the opposite when the piston is at upstroke area. In this example, the maximum tensions from $2.144 \mathrm{~m}^{3}$ to $3.216 \mathrm{~m}^{3}$ are about $104.53 \%, 102.01 \%, 100 \%, 98.37 \%$ and $97.02 \%$ of that of $2.68 \mathrm{~m}^{3}$, while the minimum tensions are about $95.56 \%, 98.16 \%, 100 \%, 101.56 \%$ and $102.90 \%$ of that of $2.68 \mathrm{~m}^{3}$.

Accordingly, the initial pressure of the HP gas has a significant influence on the tension of tensioner, while the initial volume has a relatively small impact.

Table 3

Influence of the structure parameters on the maximum tension of the tensioner.

\begin{tabular}{|c|c|c|c|c|c|}
\hline Structure parameters & $-20 \%$ & $-10 \%$ & Reference & $+10 \%$ & $+20 \%$ \\
\hline Diameter of piston & $-48.66 \%$ & $-30.56 \%$ & $693.58 \mathrm{kN}$ & $+29.11 \%$ & $+63.13 \%$ \\
\hline Initial pressure of HP gas & $-24.85 \%$ & $-10.09 \%$ & $693.58 \mathrm{kN}$ & $+8.58 \%$ & $+18.83 \%$ \\
\hline Diameter of piston rod & $+7.32 \%$ & $+3.21 \%$ & $693.58 \mathrm{kN}$ & $-5.06 \%$ & $-10.55 \%$ \\
\hline Initial volume of HP gas & $+4.53 \%$ & $+2.01 \%$ & $693.58 \mathrm{kN}$ & $-1.63 \%$ & $-2.98 \%$ \\
\hline Initial pressure of LP gas & $+0.53 \%$ & $+0.26 \%$ & $693.58 \mathrm{kN}$ & $-0.27 \%$ & $-0.53 \%$ \\
\hline Initial volume of LP gas & $+0.16 \%$ & $+0.08 \%$ & $693.58 \mathrm{kN}$ & $-0.07 \%$ & $-0.13 \%$ \\
\hline Inner diameter of piping & $+0.13 \%$ & $+0.04 \%$ & $693.58 \mathrm{kN}$ & $-0.02 \%$ & $-0.04 \%$ \\
\hline Length of piping & $-0.01 \%$ & $-0.00 \%$ & $693.58 \mathrm{kN}$ & $+0.00 \%$ & $+0.01 \%$ \\
\hline
\end{tabular}


Table 4

Influence of the structure parameters on the minimum tension of the tensioner.

\begin{tabular}{|c|c|c|c|c|c|}
\hline Structure parameters & $-20 \%$ & $-10 \%$ & Reference & $+10 \%$ & $+20 \%$ \\
\hline Diameter of piston & $-38.05 \%$ & $-12.30 \%$ & $413.86 \mathrm{kN}$ & $+22.16 \%$ & $+43.16 \%$ \\
\hline Initial pressure of HP gas & $-15.00 \%$ & $-11.39 \%$ & $413.86 \mathrm{kN}$ & $+13.89 \%$ & $+24.97 \%$ \\
\hline Diameter of piston rod & $+9.44 \%$ & $+6.07 \%$ & $413.86 \mathrm{kN}$ & $-4.13 \%$ & $-8.69 \%$ \\
\hline Initial volume of HP gas & $-4.44 \%$ & $-1.84 \%$ & $413.86 \mathrm{kN}$ & $+1.56 \%$ & $+2.90 \%$ \\
\hline Initial pressure of LP gas & $+4.28 \%$ & $+1.00 \%$ & $413.86 \mathrm{kN}$ & $-0.99 \%$ & $-1.99 \%$ \\
\hline Initial volume of LP gas & $-2.03 \%$ & $+0.82 \%$ & $413.86 \mathrm{kN}$ & $-0.60 \%$ & $-1.06 \%$ \\
\hline Inner diameter of piping & $-0.22 \%$ & $-0.07 \%$ & $413.86 \mathrm{kN}$ & $+0.39 \%$ & $+0.45 \%$ \\
\hline Length of piping & $+0.01 \%$ & $+0.01 \%$ & $413.86 \mathrm{kN}$ & $+0.01 \%$ & $+0.01 \%$ \\
\hline
\end{tabular}

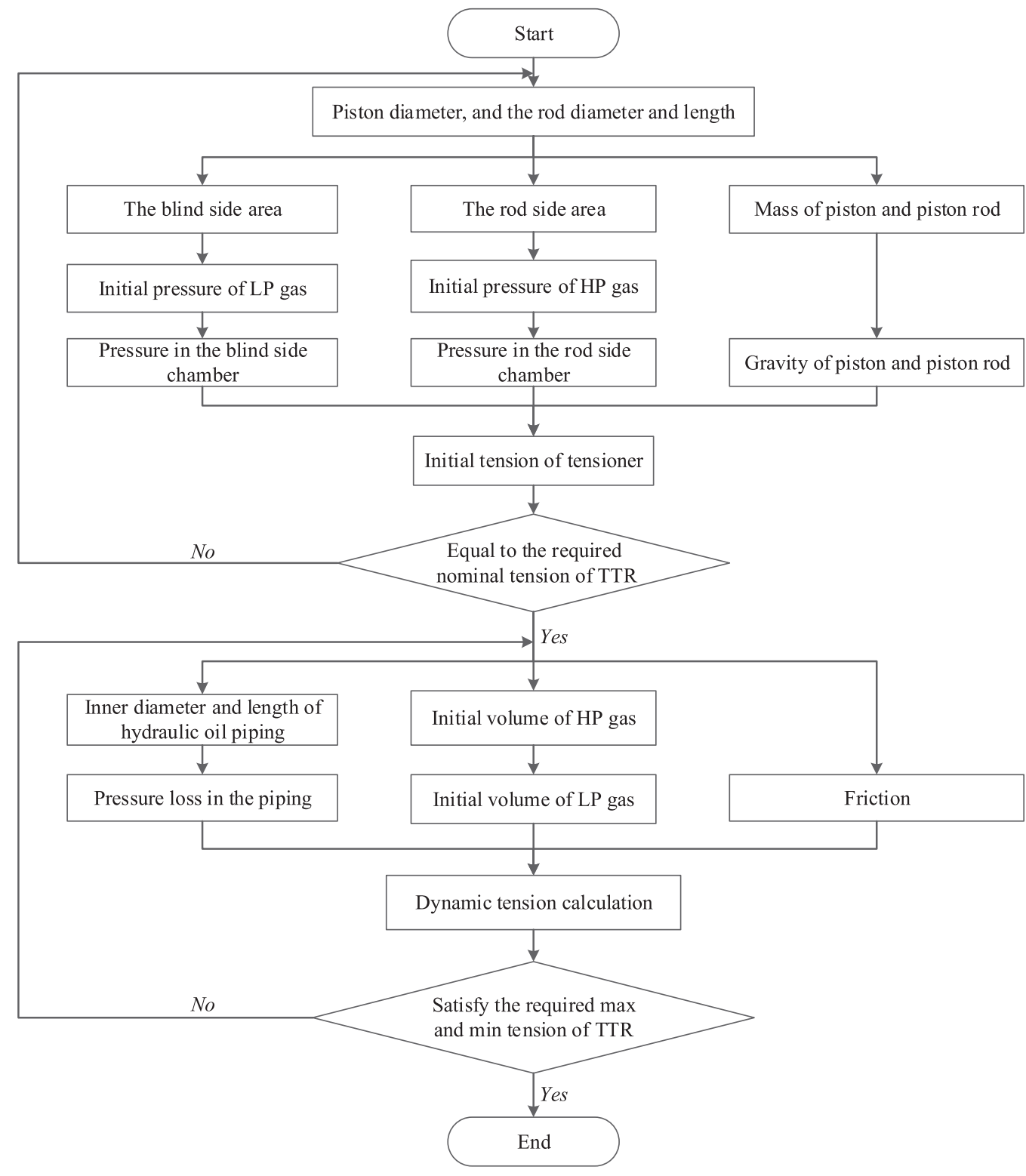

Fig. 24. Proposed HPT design guideline.

\subsection{Length and inner diameter of hydraulic oil piping}

The inner diameter and length of hydraulic oil piping have an influence on the pressure loss in the piping and further affect the tension of tensioner. According to Eq. (10), the inner diameter has an impact on all the two parts of pressure loss, while the piping length influences only the pressure loss along the hydraulic oil piping.

The variations of tension and pressure loss with different lengths
$(0.48 \mathrm{~m}, 0.54 \mathrm{~m}, 0.6 \mathrm{~m}, 0.66 \mathrm{~m}$ and $0.72 \mathrm{~m})$ with a variation gradient of $0.06 \mathrm{~m}$ (i.e. $10 \%$ of $0.6 \mathrm{~m}$ ) are shown in Figs. 20 and 21 respectively. As the length of hydraulic oil piping varies, the tension of tensioner does not show an obvious difference, which explains the relatively small impact of the piping length in this example. As shown in Fig. 21, the pressure loss increases as the piping length becomes longer.

The variations of tension and pressure loss with different inner diameters $(0.128 \mathrm{~m}, 0.144 \mathrm{~m}, 0.16 \mathrm{~m}, 0.176 \mathrm{~m}$, and $0.192 \mathrm{~m})$ with a 
variation gradient of $0.016 \mathrm{~m}$ (i.e. $10 \%$ of $0.16 \mathrm{~m}$ ) are shown in Figs. 22 and 23 respectively. In addition, the calculation result of $0.112 \mathrm{~m}(70 \%$ of $0.16 \mathrm{~m}$ ) is also considered for a more thorough comparison. The influence of inner diameter on the tension of tensioner and pressure loss becomes more and more obvious when the inner diameter decreases. As the inner diameter of piping turns into $0.128 \mathrm{~m}$ and $0.112 \mathrm{~m}$, the tension of tensioner and pressure loss changes sharply. Therefore, the inner diameter of hydraulic oil piping should not be too small.

\subsection{Discussion}

Tables 3 and 4 summarize the influence of the structure parameters on the maximum and minimum tension of the tensioner with the same variation gradient, i.e. $10 \%$ of the initial parameter. The results show that the diameter of the piston and the initial pressure of the HP gas have the most significant influence on the tension of the tensioner. Secondly, the diameter of the piston rod is also an important parameter affecting the tension behavior of tensioner. Next, the initial volume of HP gas and the initial pressure of LP gas also have some impact on the tension of the tensioner. At last, the influence of the initial volume of LP gas and the inner diameter and length of the piping is relatively small.

Accordingly, the tension of tensioner is determined by the key performance parameters analyzed above. Based on the analysis, a basic tensioner design guideline is proposed shown in Fig. 24. As shown in the guideline, after the tension demand of a TTR configuration is given, the diameter of piston, the diameter and length of piston rod, and the initial pressures of HP and LP gas should be determined first. According to the formulation $T=P_{o}\left(A_{p}-A_{r}\right)-P_{l} A_{p}-M g$, the initial tension of the tensioner is calculated and compared with the required nominal tension of TTR. If they are not equal, the initial pressure of HP gas or LP gas should be adjusted. If the calculated initial tension of the tensioner is equal to the required nominal tension, the initial volumes of HP and LP gas and the inner diameter and length of hydraulic oil piping are chosen in the next step. Based on Eq. (15), the dynamic tension of tensioner will be calculated with different calculation cases. If the dynamic tension satisfies the required maximum and minimum tension of TTR, the basic design of tensioner will be finished. If not, the tensioner performance parameters should be reconfirmed.

\section{Conclusions and future studies}

In this study, an improved mathematical model of a HPT system for TTR is established. Subsequently, the tension characteristic and key performance parameters of the HPT system are analyzed. Based on the simulation results the following remarks are abstracted:

(1) The conventional simplified model indeed overestimates the tension of tensioner as it neglects some performance parameters resulting in tension loss. The pressure of LP gas, the mass of piston and piston rod, the tension loss along piping or hose, and the friction between piston and hydraulic cylinder should be considered to reflect the actual tension characteristic of tensioner.

(2) The pressure in the rod side chamber is close but not equal to the tensioner tension, especially when the piston moves from downstroke to upstroke. Except for the pressure in the rod side chamber of the hydraulic cylinder, other tension components are ordered by the pressure in the blind side chamber, the friction, the gravity of piston and piston rod, and the inertia force of piston and piston rod.

(3) The diameter of the piston and the initial pressure of the HP gas have the most significant influence on the tension of tensioner. Secondly, the diameter of the piston rod is also an important parameter for the tension behavior of tensioner. Next, the initial volume of HP gas and the initial pressure of LP gas also have some impact on the tension of the tensioner. At last, the influence of the initial volume of LP gas and the inner diameter and length of the piping is relatively small. In addition, the inner diameter of hydraulic oil piping should not be too small.

The proposed mathematical model in this study is based on the assumption that the process of gas volume change is adiabatic. In addition, an approximate expression rather than a tedious derivation is introduced to calculate the compressed volume of hydraulic oil. Further developments may consider the rigorous derivation of the compressibility of hydraulic oil and a heat transfer process of gas volume change. Besides, the mathematical model can be further integrated in the TTR dynamic analysis process to simulate the dynamic responses of TTR.

\section{Acknowledgments}

The authors gratefully acknowledge the National Natural Science Foundation of China (Grant nos. 51609169 and 51779173) and the financial support from the GuangXi Science and Technology Major Project (AA17292007).

\section{References}

[1] X.M. Li, H.Y. Guo, F.S. Meng, Stress analysis of top tensioned riser under random waves and vessel motions, J. Ocean Univ. China 9 (3) (2010) 251-256.

[2] K.D. Do, J. Pan, Nonlinear control of an active heave compensation system, Ocean Eng. 35 (5-6) (2008) 558-571.

[3] K.D. Do, J. Pan, Boundary control of transverse motion of marine risers with actuator dynamics, J. Sound Vib. 318 (4-5) (2008) 768-791.

[4] K.D. Do, Boundary control design for extensible marine risers in three dimensional space, J. Sound Vib. 388 (2017) 1-19.

[5] K.D. Do, Stochastic boundary control design for extensible marine risers in three dimensional space, Automatica 77 (2017) 184-197.

[6] H. Gupta, V. Nava, H. Banon, et al., Determination of riser tensioner properties from full-scale data[C]//ASME, 2008 27th International Conference on Offshore Mechanics and Arctic Engineering (2008) 895-901.

[7] R. Sten, M.R. Hansen, C.M. Larsen, et al., Force variations on heave compensating system for ultra-deepwater drilling risers[C]//ASME, 2010 29th International Conference on Ocean, Offshore and Arctic Engineering (2010) 1-10.

[8] H. Lee, M. Roh, S.H. Ham, et al., Dynamic simulation of the wireline riser tensioner system for a mobile offshore drilling unit based on multibody system dynamics, Ocean Eng. 106 (2015) 485-495.

[9] Y.J. Chang, G.M. Chen, Y.Y. Sun, et al., Nonlinear dynamic analysis of deepwater drilling risers subjected to random loads, China Ocean Eng. 22 (4) (2008) 683-691.

[10] W.M. Chen, M. Li, Z.Q. Zheng, et al., Impacts of top-end vessel sway on vortexinduced vibration of the submarine riser for a floating platform in deep water, Ocean Eng. 99 (2015) 1-8.

[11] L.J. Mao, Q.Y. Liu, S.W. Zhou, et al., Deep water drilling riser mechanical behavior analysis considering actual riser string configuration, J. Nat. Gas Sci. Eng. 33 (2016) 240-254.

[12] G.L. Kuiper, J. Brugmans, A.V. Metrikine, Destabilization of deep-water risers by a heaving platform, J. Sound Vib. 310 (3) (2008) 541-557.

[13] W.M. Chen, M. Li, S.X. Guo, et al., Dynamic analysis of coupling between floating top-end heave and riser's vortex-induced vibration by using finite element simulations, Appl. Ocean Res. 48 (2014) 1-9.

[14] S. Lei, W.S. Zhang, J.H. Lin, et al., Frequency domain response of a parametrically excited riser under random wave forces, J. Sound Vib. 333 (2) (2014) 485-498.

[15] Y.B. Wang, D.L. Gao, J. Fang, Coupled dynamic analysis of deepwater drilling riser under combined forcing and parametric excitation, J. Nat. Gas Sci. Eng. 27 (2015) 1739-1747.

[16] A. Yu, Y.M. Cheng, S. Bhat, Evaluation of key hydraulic tensioner performance parameters for ultra deep water applications, 27th International Conference on Offshore Mechanics and Arctic Engineering (2008) 15-20.

[17] C.K. Yang, M.H. Kim, Linear and nonlinear approach of hydropneumatic tensioner modeling for spar global performance, J. Offshore Mech. Arct. Eng. 132 (1) (2010) 1-9.

[18] R.G. Pestana, F.E. Roveri, R. Franciss, et al., Marine riser emergency disconnection analysis using scalar elements for tensioner modelling, Appl. Ocean. Res. 59 (2016) 83-92.

[19] S.C. Li, M. Campbell, H. Howells, et al., Tension loss of hydro-pneumatic riser tensioners, 32nd International Conference on Ocean, Offshore and Arctic Engineering (2013) 9-14.

[20] S. Andersson, A. Söderberg, S. Björklund, Friction models for sliding dry, boundary and mixed lubricated contacts, Tribol. Int. 40 (4) (2007) 580-587.

[21] H.S. Kang, M.H. Kim, S.S. Bhat Aramanadka, Tension variations of hydro-pneumatic riser tensioner and implications for dry-tree interface in semisubmersible, Ocean Syst. Eng. 7 (1) (2017) 21-38. 